\title{
Certifying Health: The Unequal Legal Geographies of COVID-19 Certificates
}

\author{
Alberto ALEMANNO* and Luiza BIALASIEWICZ**
}

\begin{abstract}
This article discusses some of the challenges posed by the introduction of COVID-19 certificates as a privileged tool for opening up mobility and access in order to restore a semblance of normality to social life. While at present there is no international consensus either on how or why - such certificates should be used or on how they should be designed and applied, a growing number of countries have already introduced COVID-19 certificates in one form or another. Yet the scientific community as well as the World Health Organisation (WHO) have expressed caution, noting that such certificates might disproportionately discriminate against people on the basis of race, religion and socioeconomic background, as well as on the basis of age due to the sequencing of the vaccine rollout. Indeed, while the new COVID-19 certificates may appear to promise a magical solution enabling us to free up global mobility and reopen economies, they actually risk creating new borders and new forms of inequality through an exclusionary sorting and profiling mechanism that delimits "safe" from "unsafe" bodies, based on differential access to "immuno-privilege" - but also differential forms of "bio-securitisation". They also provide an illusion of pandemic safety - assuring citizens that through the "fetish" of the certificate "safe travel" can magically be reinstated. Securing territories and populations has always been, in Foucauldian terms, a matter of "making a division between good and bad circulation and maximizing the good circulation by diminishing the bad". We can therefore reasonably expect growing contestation, including before courts, around COVID-19 certificates in their different national and international iterations, as their inherently discriminatory nature and other unintended consequences such as those stemming from the use of persuasive - as opposed to the more traditional coercive - governmental power begin to unfold in their performative trajectory.
\end{abstract}

As the world enters into the second year of the COVID-19 pandemic, both states and international organizations are desperately looking for paths out of some of the restrictive physical distancing measures and mobility restrictions imposed to control the spread of severe acute respiratory syndrome coronavirus 2 (SARS-CoV-2). Since the start of mass vaccination campaigns in early 2021, the idea of granting special

\footnotetext{
Jean Monnet Professor of EU Law and Policy at HEC Paris, France, and Editor-in-Chief of the European Journal of Risk Regulation; email: alemanno@hec.fr. Both authors of this article co-edited the present Symposium on COVID-19 Certificates.

** Professor of European Governance and Co-director of the Amsterdam Centre for European Studies, University of Amsterdam, The Netherlands; email: L.A.Bialasiewicz@uva.nl.
} 
privileges to those who have been immunised has been gaining momentum across the world. From Israel to Switzerland to China, a number of states have already adopted broadly defined "vaccination certificates" - physical as well as digital - as they seek to reopen borders to travel, unfreeze economies from costly lockdowns and re-establish some semblance of a "new normal". Individuals in possession of such certificates could be exempt from physical restrictions and could regain full access to socioeconomic life (eg return to work or school, gain access to public or private services, including holiday resorts), as well as to national and international travel (eg being allowed to board a plane or train or cross borders by car or other modes of transportation), without - in principle - endangering others.

While at present there is no international consensus on either how - or why - such certificates should be used or on how they should be designed and applied, a growing number of countries as well as regional trade areas, such as the European Union (hereinafter EU), are moving to introduce COVID-19 certificates in one form or another. In particular, the EU is pioneering a COVID-19 certificate that covers not only those who have been vaccinated but also those who have tested negatively as well as those who have recovered from the infection. ${ }^{1}$ International as well as national health bodies have, thus far, withheld support of such certificates, cautioning against their adoption as a magic bullet to successfully manage COVID-19 risks. Both vaccination and recovery certificates are - and remain - inconsistent with the World Health Organization's (WHO) temporary recommendations for international travellers, ${ }^{2}$ with the WHO recently stating that: "At the present time, it is WHO's position that national authorities and conveyance operators should not introduce requirements of proof of COVID-19 vaccination for international travel as a condition for departure or entry, given that there are still critical unknowns regarding the efficacy of vaccination in reducing transmission". 3 The scientific community has also expressed caution. Both the German Bioethics Council ${ }^{4}$ as well as the UK's Royal Society ${ }^{5}$ published long lists of criteria that would have to be met for such certificates to fulfil their stated function: that is, protecting both personal as well as public health. Yet despite these calls for caution from both the WHO and the scientific community, the enthusiasm for such documents appears to be growing, across the globe. At the G7 Summit in June 2021, the assembled leaders called for the mutual recognition of such certificates as crucial to "helping global travel and commerce recover from the

\footnotetext{
1 Regulation (EU) 2021/953 of the European Parliament and of the Council of 14 June 2021 on a framework for the issuance, verification and acceptance of interoperable COVID-19 vaccination, test and recovery certificates (EU Digital COVID Certificate) to facilitate free movement during the COVID-19 pandemic (Text with EEA relevance), PE/25/ 2021/REV/1, OJ L 211, 15.6.2021, pp 1-22. For a detailed analysis of the EU Digital COVID Certificate, see the contributions of Iris Goldner Lang, Oskar Josef Gstrein, Evelyn Paris, Dimitry Vladimirovich Kochenov and Jacquelyn Dietrich Veraldi and to the European Journal of Risk Regulation Symposium on COVID-19 Certificates.

2 Updated WHO recommendations for international traffic in relation to COVID-19 outbreak (29 February 2020).

3 See Interim position paper: considerations regarding proof of COVID-19 vaccination for international travellers ( 5 February 2021).

4 The joint recommendations and the recommendations relating to the different positions as well as the full text of the Opinion are available (in German) at <https://www.ethikrat.org/fileadmin/Publikationen/Stellungnahmen/deutsch/ stellungnahme-immunitaetsbescheinigungen.pdf $>$.

5 The Royal Society, "Twelve criteria for the development and use of COVID-19 vaccine passports" (14 February 2021) <https://royalsociety.org/-/media/policy/projects/set-c/set-c-vaccine-passports.pdf>; see also the opinion of the Nuffield Council on Bioethics < https://www.nuffieldbioethics.org/assets/pdfs/Immunity-certificates-rapid-policybriefing.pdf $>$.
} 
shock of the pandemic". 6 This endorsement of the COVID-19 certificate as part of the "Cornwall consensus" serves to further legitimise it as a valid model within but also beyond the G7, de facto imposing it on the rest of the world. ${ }^{7}$ The push by governments has been further spurred by initiatives from the private sector, with tech giants including Microsoft and Oracle teaming up with travel industry associations such as the International Air Transport Association (IATA) to create new "global digital health passes". In the meantime, a hidden pandemic marketplace advertising fake vaccine and test certificates has grown exponentially, ${ }^{8}$ with more than 1,200 such vendors in the UK and worldwide and the German police setting up a special task force to combat the growing black market. ${ }^{9}$

Supporters of the COVID-19 certificates argue they have a critical role to play in ending restrictions imposed to curtail the spread of the pandemic, at least in countries with wide-scale access to vaccines. ${ }^{10}$ There is also the hope that they would serve to nudge the hesitant towards vaccination ("No vaccine, no certificate, no access, no life"). This challenge is becoming increasingly relevant in wealthy countries where the problem is no longer the availability and distribution of vaccines but something else entirely: pockets of vaccine hesitancy, ${ }^{11}$ if not outright anti-vaccine sentiment. ${ }^{12}$ The scale of this problem is perhaps most evident in the USA, where the take-up of vaccines has been marked by staggering divides across different locations - but also across party lines. ${ }^{13}$ In Europe and elsewhere, while the geographical differences may not be as stark, significant differences in vaccine take-up are visible, most markedly among ethnic minority groups as well as in religious communities. ${ }^{14}$

The unequal take-up of vaccination is one of the factors highlighted by opponents of the COVID-19 certificates, noting that along with their considerable scientific, practical and legal challenges, they also risk accentuating existing inequities. The use of such certificates - in either physical or electronic form - would simply exacerbate the harm inflicted by COVID-19 on already vulnerable populations, especially in regions of the world where neither vaccines nor tests are available. ${ }^{15}$ Even in those countries

\footnotetext{
6 G7 Health Ministries' Communiqué (3-4 June 2021) states: "We are committed to work as G7 countries towards a process of mutual acceptance of COVID-19 certificates". See also Carbis Bay G7 Summit Communiqué, "Our Shared Agenda for Global Action to Build Back Better" (11-13 June 2021).

7 On this point, see Häkli in this Symposium.

8 J Grierson, "Fake Covid vaccine and test certificate market is growing, researchers say" (The Guardian, 16 May 2021).

9 BBC, "Coronavirus: Germany fights trade in fake Covid vaccine certificates" (3 June 2021).

10 Public support for COVID-19 certificates is relatively high across countries. See, eg, IPSOS and World Economic Forum, "Global public backs COVID-19 vaccine passports for international travel" (28 April 2021). See also YouGov, who show that in the UK six in ten Britons (61\%) support the idea of COVID certificates - including over a quarter (28\%) who are strongly supportive of such plans, available at $<$ https://docs.cdn.yougov.com/oe2nlxn3h9/YouGov\%20The\% 20Times\%20COVID\%20certificates.pdf $>$.

11 MS Razai, UAR Chaudhry, K Doerholt, L Bauld and A Majeed, "Covid-19 vaccination hesitancy" (2021) BMJ 10.1136/bmj.n1138

12 J Ashton, "COVID-19 and the anti-vaxxers" (2021) 114(1) Journal of the Royal Society of Medicine 42-43.

13 For the most recent data, see <https://coronavirus.jhu.edu/vaccines/us-states $>$.

14 For the UK, see Razai et al, supra, note 11 . For a seventeen-country study on vaccine hesitancy, see <https://www ssph-journal.org/articles/10.3389/ijph.2021.636255/full>.

15 While vaccine coverage in most high-income countries was approaching $50 \%$ or higher at the time of writing, in the rest of the world it remained below 2\% - see Financial Times, "Letter: G20 vaccine pledges are a fraction of what we need" (8 June 2021). See also The Economist Intelligence Unit (EIU), "More than 85 poor countries will not have widespread access to coronavirus vaccines before 2023" (27 January 2021).
} 
with mass vaccination campaigns in place such as the UK, significant opposition has been voiced against the implementation of "vaccine certificates", such as the report produced by Members of Parliament on the Public Administration and Constitutional Affairs Committee noting that such certificates "would likely disproportionately discriminate against people on the basis of race, religion and socioeconomic background, as well as on the basis of age due to the sequencing of the vaccine rollout". ${ }^{16}$ On this basis, opponents argue that COVID-19 certificates should not be used either within individual countries or as a tool to unlock international travel. ${ }^{17}$

It is against this backdrop that the European Journal of Risk Regulation has convened this Symposium on COVID-19 Certificates to mobilise the research community that has been working on the issue from a variety of regional and disciplinary perspectives and to gather actionable evidence that might advance the state of knowledge and inform policymaking. In this introductory piece, we outline some of the most important findings of existing research, highlighting the challenges posed by the introduction of such certificates as a privileged tool to open up mobility and access in order to restore a semblance of normality to social life.

\section{The Regulatory politics (AND GeOPOlitics) of COVID-19 CeRTIFICATES}

COVID-19 certificates cannot (and should not) be examined in isolation from the overall broader regulatory response to the COVID-19 pandemic, which has been characterised by widespread limitations on different human rights. Those have ranged from limitations to mobility and curfews, to the closure of educational institutions and commercial activities, the necessity of which has increasingly been contested. ${ }^{18}$ The rationale for the creation of COVID-19 certificates must therefore be found in the need to alleviate some of the limitations placed on the general population. As such, COVID-19 certificates are the direct by-product of the regulatory response to COVID-19, and they represent an attempt at a compromise solution enabling the striking of a balance between two conflicting goals: individual freedom on the one hand versus public health protection on the other.

When examining the multiple implications stemming from the introduction of these documents, it is key to acknowledge the existence of several models by distinguishing them based on their coverage (eg recovery, testing, vaccination) and use (eg domestic and/or cross-border travel). Each of them raises specific ethical, socioeconomic and legal concerns that are discussed across the various contributions to this Symposium, which assess a range of national and international "models". Due to its uniquely wide coverage and pioneering nature, the EU Digital COVID Certificate - created by the EU and its twenty-seven Member States in the spring of 2021 - offers a rich case study and is the focus of many of the articles gathered here.

\footnotetext{
16 R Syal, "Covid passports will be discriminatory and must be scrapped, say MPs" (The Guardian, 12 July 2021) available at $<$ https://www.theguardian.com/politics/2021/jun/12/covid-passports-will-be-discriminatory-and-must-bescrapped-say-mps $>$.

17 See, eg, A Alemanno and L Bialasiewicz, "The dangerous illusions of an EU "vaccine passport", (OpenDemocracy, 9 March 2021).

18 See, eg, A Gross, "Like a dystopian nightmare: human rights, democracy, and politicization and securitization of health in constitutional and global health law in the shadow of the COVID-19 crisis" (Mishpat Umimshal, forthcoming 2021); TH Brandes, "A year in review: COVID-19 in Israel: a tale of two crises" (Verfblog, 13 April 2021) <https:// verfassungsblog.de/a-year-in-review-covid-19-in-israel/>.
} 
The EU Digital COVID Certificate strives to ensure the free movement not only of those who have been vaccinated, but also of those with a negative COVID-19 test be it through a molecular or an antigenic test - as well as those who have recovered from COVID-19. As outlined in the contribution by Iris Goldner Lang, "this way, EU certificates will promote individualised risk assessment when relying on public health justifications, instead of more generalised and systematic restrictions, such as entry bans, quarantines or [polymerase chain reaction (PCR)] tests for everybody". At the same time, a key rationale of the EU Digital COVID Certificate lies in an attempt by EU Member States to keep their vaccination, testing and recovery certificates interoperable. In other words, as many EU countries began to move to set up their own national (and even regional) certification systems in the spring of 2021, the EU stepped in to ensure that these would be fully interoperable, so as to not create extra restrictions to free movement within and across the Union. Despite this stated aim, however, insofar as the conditions for the issuance of the COVID-19 certificate vary from Member State to Member State, the risk exists that a COVID-19 certificate holder may be subject to additional "national" requirements, such as quarantine or testing. This would defy the certificate's declared purpose of unlocking free movement.

Second, the (currently unspecified) duration of the EU Digital COVID Certificate - as well as other certificates - might hide major unintended consequences that might manifest themselves beyond their "temporary" nature. Indeed, beyond a variety of concerns regarding their effectiveness, the contribution by Oskar Josef Gstrein warns that these certificates "might transform into a general-purpose infrastructure that will keep privacy advocates busy for years to come". In particular, Gstrein's article highlights concerns regarding the potential repurposing of data and data retention. While the EU has not established a central database for the certificates, ${ }^{19}$ questions persist regarding the oversight of data storage at the national level.

Third, there is also an important geopolitical dimension to the way in which COVID-19 certificates are being developed. While the often-repeated mantra of political leaders continues to be "interoperability" and "mutual recognition" (whether in the case of the EU Digital COVID Certificate or also globally, as declared at the last G7 Summit), such projected acceptance comes with its own forms of exclusion. As Dimitry Vladimirovich Kochenov and Jacquelyn Dietrich Veraldi outline in their contribution, the EU Digital COVID Certificate not only risks creating forms of exclusion between the vaccinated/recovered and the unvaccinated/non-recovered, but also "explicitly permits further discrimination among those that are vaccinated", excluding from certification those who are vaccinated with a non-European Medicines Agency (EMA)-approved vaccine. The Digital COVID Certificate cannot, indeed, be issued for non-EMA-approved vaccines, thereby, as the authors note, "effectively punishing Member States for making their own judgment about the best strategy to save the lives of their own citizens in the context of the pandemic in a way

\footnotetext{
19 European Data Protection Board and European Data Protection Supervisor, "EDPB-EDPS Joint Opinion 04/2021 on the Proposal for a Regulation of the European Parliament and of the Council on a Framework for the Issuance, Verification and Acceptance of Interoperable Certificates on Vaccination, Testing and Recovery to Facilitate Free Movement during the COVID-19 Pandemic (Digital Green Certificate)" (2021) Version 1.1, 6 <https://edpb.europa. eu/sites/edpb/files/files/file1/edpb_edps_joint_opinion_dgc_en.pdf> (last accessed 29 June 2021).
} 
that is capable of fully complying with EU law". The politics of certification within the EU is in fact firmly bound up with broader geopolitical orientations (whether towards Russia or China), with political leaders in Member States such as Poland declaring explicitly that they would not waive free movement restrictions for EU citizens inoculated with the Russian-made Sputnik V vaccine ${ }^{20}$ (this includes at the time of writing a considerable percentage of Hungarian citizens and, as of the start of June 2021, also of Slovakia). ${ }^{21}$ As Kochenov and Veraldi conclude, in such positionings the "politics of inter-state relations seems to overtake, in practice, the stated public health concerns".

Fourth, the fragmented politics and geopolitics of vaccine certification within the EU are further accentuated when we cast our gaze at the global scale. The contribution by Tsung-Ling Lee focuses on Taiwan, hailed in the early stages of the pandemic as a success story in managing the spread of the virus, but subsequently penalised by difficulties in vaccine procurement, being very much the fruit of the island nation's complex geopolitical positioning. ${ }^{22}$ Not only is the island nation excluded from participating at the WHO because of its contentious political status, but due to Taiwan's relatively successful pandemic response and gross domestic product (GDP), it is also considered a low priority for vaccine distribution through the international COVID-19 Vaccine Global Access Facility (COVAX). All the while, as Lee notes in her piece, Taiwan remains "caught in strategic competition and economic rivalry between the USA and China", reflected directly in internal political debates over which vaccines can and should be purchased - the Chinese-made Sinovac or Pfizer-BioNTech? Its fate long determined by geopolitical competition, Taiwan's limited access to vaccination risks marginalising it further as the rollout of COVID-19 certificates begins to gain ground internationally.

\section{To What PURpose? COVID-19 CERTIFICATES AND THEIR AMBIGUOUS RATIONALES AND USES}

One of the common features of COVID-19 certificates is the lack of clarity surrounding their policy objective(s). ${ }^{23}$ Decision-makers were (and remain) unclear about the exact purposes that the COVID-19 certification policy was meant to serve. While some highlight the protection of individuals' health and of public health, with the aim of minimising restrictions and facilitating a safer reopening of economic and social activities, others have argued that this policy is also intended to encourage vaccination and to overcome vaccine hesitancy. ${ }^{24}$

\footnotetext{
20 Reuters, "Poland does not plan to buy Russian vaccine, says minister" (Reuters, 4 March 2021) <https://www. reuters.com/article/us-health-coronavirus-poland-russia-idUSKBN2AW1WC $>$.

$21<$ https://www.euronews.com/2021/06/07/slovakia-is-second-eu-country-to-roll-out-russia-s-sputnik-v-covid-19vaccine $>$.

22 Lee, in this Symposium.

23 This is a cross-cutting theme discussed in many of the contributions to this Symposium. See, in particular, Goldner Lang, Luster et al, Paris and Gstrein.

24 In the public health literature, "vaccine hesitancy" refers to delays or refusals of vaccination that could stem from various reasons, including lack of time, knowledge, awareness or access. See R Butler, NE MacDonald and SAGE Working Group on Vaccine Hesitancy, "Diagnosing the determinants of vaccine hesitancy in specific subgroups: the guide to tailoring immunization programs (TIP)" (2015) 32(34) Vaccine < https://www.sciencedirect.com/ science/article/pii/S0264410X15005022>.
} 
This ambivalence regarding the goals pursued is extremely problematic as it affects the legality and notably the proportionality assessment of such certificates. As highlighted by Tamar Luster, Einat Albin, Aeyal Gross, Miriam Tabenkin and Nadav Davidovitch in their contribution, while any and all COVID-19 certificates must be designed with the utmost care in order to prevent a disproportionate violation of the human rights of the non-vaccinated and the public at large, those "that are used towards a broader purpose of incentivising immunisation are set to raise far more legal difficulties". ${ }^{25}$ In other words, any balancing of conflicting rights inherent to any proportionality review presupposes a clear identification of the objective sought by the contested measure and the use followed by the latter. Thus, as Evelyn Paris argues in her article, "immunity or recovery certificates pose similar issues to vaccination certificates; however, due to the different type of incentive that they provide, they might be even more untenable from a legal and ethical standpoint". ${ }^{26}$ In any event, as Sarah Ganty also warns in her contribution, whether it is for questions of accessibility, administrative expediency, hesitancy, mistrust or other reasons, public authorities are called upon "to take into account the exclusionary dimension that the lack of a vaccination certificate will have, especially for vulnerable socioeconomically disadvantaged groups who have a long history of discrimination". ${ }^{27}$

Thus, as illustrated by Luster et al, it is no surprise that specific aspects of the COVID-19 certificate model were challenged before Israel's Supreme Court, from imposing a "Green Pass" requirement on Israel's public memorial ceremonies, ${ }^{28}$ to the decision to issue the "Green Pass" only in Hebrew and English, without including the Arabic language. ${ }^{29}$ We can reasonably expect many more cases to be brought against the legality of COVID-19 certificates in their different national and international iterations, as their inherently discriminatory nature and other unintended consequences begin to unfold. While at the moment the requirements of existing (or planned) COVID-19 certificates are implemented on a limited number of public activities, this policy could be dramatically broadened, de jure or de facto, and lead to much more significant violations of rights. In the EU context, the creation of a COVID-19 certificate de facto renders the presentation of this document a prerequisite for exercising free movement within the Union, which per se clashes with the Treaty-enshrined principle of free movement and the Schengen code. As stated by Goldner Lang, the "certificates will be an EU measure restricting free movement of EU citizens, as they will limit what is supposed to be free cross-border travel". ${ }^{30}$ As such, they will be subject to the necessity test, in order to make sure that there is no less restrictive alternative that achieves the same aim equally successfully.

25 Luster et al, in this Symposium.

26 Paris, in this Symposium.

27 Ganty, in this Symposium.

28 Israel's Supreme Court had denied the request for immediate temporary injunction, thus giving way to holding Israel's national memorial ceremonies under the "Green Pass" requirement. HCJ 2254/21 Individual Freedom Protectors v. Director of Health Ministry (Interim decision), Nevo Legal Database (4 April 2021) (Isr.).

29 HCJ 1935/21 Adalah - The Legal Center for Arab Minority Rights in Israel v. Minister of Health (petition is awaiting the state's response), Nevo Legal Database (4 April 2021) (Isr.).

30 Goldner Lang, in this Symposium. 
However, when considering whether there is a less restrictive method of enabling free movement while preserving the same level of public health protection, Goldner Lang observes that in the COVID-19 world, "the alternative to Digital Green Certificates is not unrestricted free movement, but even more restrictions", such as quarantines, selfisolation and/or testing requirements for everybody, or even complete entry bans. And what if - as is currently the case - the recipient Member State remains free to consider a validly issued COVID-19 certificate presented by a holder as valid but insufficient? Indeed, insofar as the twenty-seven Member States continue to govern the conditions determining the issuance of the certificate, be it a vaccine, test or proven immunity, they also remain free to impose - within the limits of proportionality - extra requirements, such as quarantines or testing, on certificate holders.

Moreover, as Evelyn Paris recalls in her contribution, vaccination against a disease or recovery from a disease (or lack thereof) as a health status is a relatively novel concept for legal protection, despite historical examples of the discriminatory impacts of immunoprivilege, such as with the management of the yellow fever epidemic in New Orleans during the nineteenth century. This is why the International Health Regulations (IHR) exceptionally foresee provisions for yellow fever as the only disease for which countries can require proof of vaccination. ${ }^{31}$ Ultimately, the introduction of these measures must then be understood in the context of the pressure that governments might face from businesses seeking to adopt policies that return employees to the workforce, with corporate entities being the beneficiaries of the immuno-capital of workers. In the USA, many colleges and universities have already declared that they will bar unvaccinated students in the coming academic year, ${ }^{32}$ while some military bases are imposing further restrictions on soldiers who refuse the jab. Likewise, employers have begun to make the unvaccinated subject to stricter regimes than those who have accepted the jab. This raises a deeper problem. Although choice preserving, these measures de facto render vaccination mandatory to citizens, and the certificates contribute to institutionalising such an approach. Yet it will ultimately be up to public authorities, not private actors, to defend the legality of COVID-19 certificates before courts.

\section{Mobility FOR WhOM? COVID-19 CERTIFICATES AND THE UNEQUAL BORDERING OF BODIES}

Just as individuals' potential exposure to COVID-19 and their health outcomes once infected have been highly differentiated across places and populations, such differential impacts have also been observable in the measures enacted by states and international bodies to govern pandemic risk. The forms of regulatory intervention and restrictions on individual freedoms described in Section I above did not impact everyone everywhere equally. As political geographer Anne-Laure Amilhat-Szary

\footnotetext{
31 WHO, "Interim position paper: considerations regarding proof of COVID-19 vaccination for international travellers" (5 February 2021).

32 Also creating further forms of exclusion since only certain vaccines are accepted: see $<$ https://www.nytimes.com/ 2021/06/03/us/coronavirus-vaccine-college-students.html>.
} 
wrote at the closing of the first year of the pandemic, "paradoxically, those who are today able to confine themselves in good conditions are exactly the same people who had access to freedom of movement in pre-COVID times. In other words, the same people who possess a degree of global autonomy enabling them to choose the interactions which globalize them". ${ }^{33}$ Such individuals possess what Amilhat-Szary has described as an elevated degree of "borderity" 34 - that is, the unequal ability to cross borders. As she noted, in the case of the pandemic, "borderity" manifested itself into the unequal ability not to cross borders, thanks to the capacity to confine oneself, which ultimately derives from the same process as being able to legally cross a border.

As several contributions in this Symposium highlight, in particular Ganty's, just as pandemic restrictions impacted individuals and populations in different ways based on their different capacities to "border", the COVID-19 certificates as bordering tools risk further exacerbating such inequalities. The piece by Kochenov and Veraldi ${ }^{35}$ warns exactly of the perils of the "passportisation" of vaccine or immunity status, noting that "in a world of "passport apartheid', 36 any new passport - electronic or physical, necessary or 'optional' - is always an addition to the list of the grounds of possible exclusion and discrimination". This is also the specific focus of Jouni Häkli's contribution, which notes that while the new "vaccine passports" are presented, just like national passports, as uniform and standardised (and, as such, "democratic"), they are far from it. ${ }^{37}$ Reviewing the longer histories of attempts to govern international mobility, Häkli notes the sorting function of such documents in maintaining the hierarchies of the global mobility regime and their capacity to regulate human corporeal mobility across territorial boundaries, facilitating some while obstructing others. Indeed, as he concludes, COVID-19 certificates risk "deepening the divisions between affluent and disadvantaged travellers from the Global North and the Global South. Even though the European Commission is keen to stress that 'people without such a certificate must still be able to travel and that being in possession of a certificate is not a prerequisite of exercising the right to free movement or other fundamental rights, ${ }^{38}$ such concessions are not extended to irregularised or partially documented migrants within Europe, let alone those seeking to enter the EU to seek asylum or protection".

Martina Tazzioli's contribution extends this analysis, observing that - historically pandemics have been moments in which new racialised borders have been enforced, with the regulation of disease serving as a powerful tool to regulate populations as well. Her piece comments on the multiplication of borders under COVID-19 and the

33 A-L Amilhat-Szary, "Those who are confined are also the most mobile!" in C Wille and R Kanesu (eds), Bordering in Pandemic Times: Insights into the Covid-19 Lockdown, UniGR-CBS Borders in Perspective, thematic issue, (University of Luxemburg and Trier University 2020).

34 A-L Amilhat-Szary and F Giraut, Borderities and the Politics of Contemporary Mobile Borders (London, Palgrave Macmillan 2015).

35 Kochenov and Veraldi, in this Symposium.

36 DV Kochenov, "Ending the passport apartheid. The alternative to citizenship is no citizenship - a reply" (2020)

18(4) International Journal of Constitutional Law 1525-30.

37 Häkli, in this Symposium.

38 European Commission, "Communication from the Commission - a common path to safe and sustained reopening” <https://eur-lex.europa.eu/legal-content/EN/TXT/PDF/?uri=CELEX:52021DC0129\&from=EN>. 
accentuation of both class-based and racialised mobility restrictions. These have been visible in the control of national borders, but equally in the unequal enforcement of hygienic-sanitary borders within states (such as lockdowns and other similar measures). As Tazzioli demonstrates, states have implemented a variety of discriminatory containment measures, confining migrants in the name of both their own protection against the virus and in order to protect the "common good" of the national citizenry. An example that comes to mind is the illegal confinement of migrants on "quarantine ships" by the Italian state. ${ }^{39}$ The proposed COVID-19 certificates, Tazzioli notes, risk only further "reinforcing health nationalisms and ... multiplying racialised hierarchies in the right to mobility", ${ }^{40}$ as any reflection on the regulation of borders and mobility in the pandemic cannot be separated from a wider reflection on (un)equal access to health and protection.

\section{Governing the PANDEMIC THROUGH DATA: COVID-19 CERTIFICATES, DATA}

\section{PRIVACY AND DATA JUSTICE}

The risks of unequal forms of bordering being exacerbated by the use of COVID-19 certificates become further compounded by the ways in which highly sensitive personal and health data are being datafied in the creation of these "pandemic passports". We noted already in Section II some of the questions being raised regarding the precise purpose and duration of these instruments, and Gstrein's contribution to this Symposium provides an important series of warnings regarding the potential "spill-overs" of the EU COVID Certificate. As he notes, the risk is that the Certificate becomes a "general-purpose infrastructure" whose operational structure as well as database of highly sensitive personal information will outlast the pandemic and will be able to be easily repurposed for a variety of needs, from health profiling to national security considerations. The hasty way in which the Certificate has been rushed through by the European Commission as an "emergency" measure, without a full impact assessment and without detailed technical specifications developed on the basis of existing EU legislation, ${ }^{41}$ raises a variety of questions regarding data protection, data safety and data proportionality. As Gstrein asks, how can we make sure that the Certificate contains only the minimum information necessary to achieve the facilitation of free movement?

The contribution by Janet Hui Xue raises similar questions, comparing the EU's attempts to develop the COVID Certificate to the challenges faced by the Chinese Health Code System (HCS), implemented as of 2020, albeit in a widely different geopolitical and regulatory environment. In particular, the author focuses on what she terms the "algorithmic vulnerabilities" inherent in implementing such certificates that aim to improve the governance of collective health and social protection through

\footnotetext{
39 M Tazzioli and M Stierl, "Europe's unsafe environment: migrant confinement under Covid-19" (2021) Critical Studies on Security 10.1080/21624887.2021.1904365.

40 Tazzioli, in this Symposium.

41 See, eg, Art 5 GDPR.
} 
datafication. ${ }^{42}$ Xue notes how the algorithms designed to support such large-scale health systems risk reinforcing existing vulnerabilities and forms of exclusion, while also potentially creating new iniquities. Importantly, she also points to the direct collaboration between private and public actors in designing as well as implementing the certificates in the case of the Chinese HCS, two large technology corporations entrusted with the deployment of the system that also relies on an existing communication app. Xue - like Gstrein - also queries the potential longer-term effects of the HCS, asking how to guarantee against potential future misuse of data, on the part of both the state and the corporate entities involved in the data collection, data sharing and data processing.

The role of private actors in the creation of COVID-19 certificates around the world is also the focus of the article by Sara Helen Wilford, Neil McBride, Laurence Brooks, Simisola Akintoye, Adebowale Owoseni, Tonii Leach, Catherine Flick, Malcolm Fisk and Martin Stacey. As the contribution notes, the development of the certificates involves a variety of technology companies, digital platforms and networks operating "in an ecosystem in which regulation is weak and risks are significant". ${ }^{43}$ Their paper examines four leading technical proposals developed by private companies for digital vaccine passports: (1) the Vaccination Credential Initiative (VCI), an alliance of twelve technology and health service providers, including Microsoft, Oracle and the Mayo Clinic; (2) the COVID-19 Credentials Initiative (CCI) developed by the Linux Foundation; (3) the IBM Digital Health Pass; and (4) the IATA Travel Pass Initiative, already in use on Singapore Airlines since March 2021. The analysis presented assesses the various risks of the technologies adopted to create the certificates, such as blockchain. As the authors write, the use of blockchain raises numerous concerns regarding issues such as anonymity, erasure and data control. Moreover, they also point to the risks inherent to the use of open-source systems and a reliance on data networks that lie beyond the remit of traditional regulatory domains.

The article by Stefania Milan, Michael Veale, Linnet Taylor and Seda Gürses takes this critique further still by commenting on the wider risks of "governance by data infrastructure" 44 that diverts regulatory power away from governmental bodies to forprofit contractors. As the authors argue, the proposed COVID-19 certificates are simply the latest entry in a series of risk-reduction technological solutions that, from the start, have characterised the response to the COVID-19 crisis: from national contact tracing apps aimed at monitoring public health and regulating sociality, to predictive analytics software to support policymakers in strategic decisions such as the imposition of territorially selective lockdowns and curfews. All of these tools many of which are still in use - forms part of an ever-growing set of data infrastructure with regulatory functions for the governance of social, political and economic life. Digital COVID-19 certificates as part of this wider infrastructure are marked by a variety of risks. First, they establish hierarchies between the certified and the uncertified, fixing individual immunological profiles. Second, they create exclusive markets (and thus also regulatory power) for the actors involved in

\footnotetext{
2 Xue, in this Symposium.

43 Wilford et al, in this Symposium.

44 Milan et al, in this Symposium.
} 
developing and implementing the technology. Third, they contribute to creating further forms of exclusion by appealing to a rhetoric of individual freedom and the "right" to live untrammelled by COVID-19 restrictions - a rhetoric, as the authors observe, that risks undermining the collective response and solidarity necessary to combat the negative effects of the pandemic on communities: local, national or global.

Apart from these risks - also identified by many of the other contributions to this Symposium - the paper by Milan et al also points to another crucial aspect of the certificates: that they may act as powerful performances of security - performances whose effects are, nevertheless, very real. As we have written elsewhere, ${ }^{45}$ the EU Digital COVID Certificate, from its very first proposals, purported to provide an illusion of pandemic safety - assuring European citizens that, through the "fetish" of the certificate, "safe free movement" could magically be reinstated. Such performances are powerful rhetorical tools and, in the case of the European Commission, the proposals for the certificate were also addressed at re-establishing trust in the EU's handling of the pandemic response, affirming the Commission's agency in re-establishing control over "dangerous" viral flows and, in so doing, facilitating "safe" travel.

However, the performative aspect of the COVID-19 certificates, as Milan et al note, is based on a highly problematic fixing of individual profiles of danger and safety. In establishing a digital COVID-19 immunity profile, the certificates "stabilise what is a discursive object of scientific research into an attribute that carries across contexts and applications". This "immunity stamp", they note, "effectively introduces the idea for the first time that someone can be certified as immune, rather than just vaccinated. This constitutes a new, commoditised identity that, in turn, has value for both the individual and the authorities certifying them - a value that is different from the more general, public health-related contribution of decreasing the communicability of COVID-19 overall". ${ }^{46}$ This is problematic for a variety of reasons: most obviously because, as the most recent studies have demonstrated ${ }^{47}$ the ability to sustain immunity to COVID-19 is highly variable. Indeed, from a scientific point of view, immunity is a moving target, as immune response fades and viral variants may escape existing immunological protection (autonomous as well as vaccine-generated). As Milan et al argue, immunity for the purpose of certification cannot thus be considered a static status that relates to an individual and as such can be "passportised", but rather is "an uncertain, contextually situated cluster of indicators primarily relating to a best guess at transmission risk". 48

\section{Conclusions}

Mounting evidence shows that the spread of COVID-19 has been profoundly unequal across the world, with some places and populations much more likely to be exposed

\footnotetext{
45 Alemanno and Bialasiewicz, supra, note 17.

46 Milan et al, in this Symposium.

$47 \mathrm{~K}$ Vanshylla et al, "Kinetics and correlates of the neutralizing antibody response to SARS-CoV-2 Infection in Humans" (2021) Cell Host \& Microbe 10.1101/2021.01.26.428207.

48 Milan et al, in this Symposium.
} 
to the virus, to fall seriously $\mathrm{ill}^{49}$ and to lack adequate health resources including, now, access to vaccination. ${ }^{50}$ While the new COVID-19 certificates may appear to promise a magical solution enabling us to free up global mobility and reopen economies, as the contributions in this Symposium caution, they actually risk creating new borders and new forms of inequality through an exclusionary sorting and profiling mechanism that delimits "safe" from "unsafe" bodies based on differential access to "immunoprivilege" - but also differential forms of "bio-securitisation".

Writing on the governance of COVID-19, Engin Isin and Evelyn Ruppert note how responses to the pandemic brought together "sovereign, disciplinary and regulatory power", as well as what they term "sensory" or bio-securitising power, long a prerogative of the modern state, but that the pandemic made all too visible for the first time in its unequal deployment. ${ }^{51}$ Securing territories and populations has always been, in Foucauldian terms, "a matter of organizing circulation, eliminating its dangerous elements, making a division between good and bad circulation, and maximizing the good circulation by diminishing the bad". ${ }^{52}$ In the governance and attempted regulation of pandemic risk, this became starkly evident.

The COVID-19 certificates, indeed, aim to institutionalise and "passportise" forms of bio-securitisation that states have been attempting to implement since the start of the twenty-first century. As political geographers including Alan Ingram ${ }^{53}$ and Kezia Barker $^{54}$ have argued long before the current pandemic, states' bio-security politics always needed to negotiate a balance "between too much and too little regulation, as in the spaces in which it operates it is not the only concern, competing with a manifold of other circulations, driven by different forces":

From simply arresting circulation through the categorization, demarcation and protection of territory, biosecurity came to be understood as a practice concerned with its facilitation and optimization. Rather than in conflict with global trade, travel and contemporary neoliberal life more broadly ... biosecurity emerged as a practice that facilitates these flows by attempting to remove their risky or negative elements. ${ }^{55}$

The stated aim of the COVID-19 certificates to "facilitate safe free movement" (as in the case of the EU Digital COVID Certificate) must thus be assessed in its myriad broader

49 See, among others, B Burström and W Tao, "Social determinants of health and inequalities in COVID-19" (2020) 30(4) European Journal of Public Health 617-18; J Patel, "Poverty, inequality and COVID-19: the forgotten vulnerable" (2020) 183 Public Health 110-11; R Blundell, "COVID-19 and inequalities" (2020) 41(2) Fiscal Studies 311-13; C Bambra, R Riordan, J Ford and F Matthews, "The COVID-19 pandemic and health inequalities" (2020) 74 Journal of Epidemiology and Community Health 964-68.

50 Ganty, in this Symposium.

51 E Isin and E Ruppert, "The birth of sensory power: how a pandemic made it visible?" (2020) 7(2) Big Data and Society $1-15$.

52 M Foucault, Security, Territory, Population: Lectures at the College de France, 1977-78 (London, Palgrave Macmillan 2007) p 18.

53 A Ingram, "The new geopolitics of disease: between global health and global security" (2005) 10 Geopolitics 522-45.

54 K Barker, "Biosecurity: securing circulations from the microbe to the macrocosm" (2015) 181(4) The Geographical Journal 357-65.

55 ibid, 358 (emphasis added). 
implications. These certificates warrant critical examination not simply as temporary tools for the regulation and governance of the pandemic, but also in terms of their potential implications for the wider governance and regulation of populations and territories, including the regulation of access to fundamental rights and the use of persuasive - as opposed to the more traditional coercive - governmental power. ${ }^{56} \mathrm{We}$ hope that the contributions in this Symposium help shed light on some of these implications, at both the national as well as the global scale.

\footnotetext{
56 A Alemanno and A Spina, "Nudging legally: on the checks and balances of behavioural regulation" (2014) 12(2)
} International Journal of Constitutional Law 429-56. 